\title{
Research Progress on Lympho Proliferative Diseases after Lung Transplantation
}

\author{
Yue Ma, Jun Chen* \\ Department of Lung Cancer Surgery, Tianjin Medical University General Hospital, China
}

Received: 制 August 03, 2018; Published: 制 August 13, 2018

*Corresponding author: Jun Chen, Department of Lung Cancer Surgery, Tianjin Medical University General Hospital, Tianjin 300052, China

\begin{abstract}
With the development of surgical methods and pharmaceutical preparations, more patients with benign end-stage lung disease can receive treatment of lung transplants. Not only the number of surgeries has increased to 4,000 per year, but also the survival time has been growing longer. Ten years ago, a lot of medical experts thought that post-transplant lymphoproliferative disease was a rare disease, but this disease has received more and more attention because of increasing of surgeries. PTLD is a serious and rare post-transplant complication. Compared with other organ transplants, the incidence of heart, lung, and heart lung transplantation is extremely high. The 5 -year survival rate is $29 \%$, and the median survival period is 10 month. Risk factors for morbidity are related to the use of immunosuppressive agents, viral infections, type of transplanted organ, gender, age et al. This article will describe the incidence, risk factors, pathogenic mechanism, treatment methods and latest research progress of lymphoproliferative diseases after lung transplantation recently by providing new ideas on hotspots.
\end{abstract}

Keywords: Lung Transplantation; Post Transplant Lymphoproliferative Disorders; Immunosuppressants; Viral Infection

\section{Introduction}

Lung transplantation is the only effective way to treat benign lung disease of end-stage. Vladimir performed lung transplant surgery on animals for the first time 70 years ago epically [1]. Soon after, Hardy did the first human lung transplantation 12 years later [2]. But patient only lived 42 days after the transplant by limiting to the development of surgical techniques and drugs. The emergence of immunosuppressants represented by cyclosporine (CsA) in 1983 significantly pulled the survival rate after lung transplantation to a new level. Afterwards, the median survival time after transplantation can reach 5.3 years [3]. Nowadays there are about 4,000 lung transplants per year, including 200 in China. Most of medical experts initially thought that Post-transplant lymphoproliferative disorders (PTLD) was a rare disease, which was been known as a mega misunderstanding presently by discovering from the results of research in the last decade and the increase in surgical patients as well. Immunosuppression and Epstein-Barr virus (EBV) infection are two the most relevant risk factors about PTLD [4]. This article will elaborate advances in research on posttransplant lymphoproliferative disorders after lung transplantation in recent years and put forward prospects at the same time.

\section{Lung Transplantation Indications and Common Compli- cations}

Lung transplant indications are generally benign lung disease of end-stage, such as advanced chronic obstructive pulmonary disease (COPD), idiopathic pulmonary fibrosis, cystic fibrosis, diffuse resistance bronchial expansion, et cetera. Usually clinicians do not recommend lung transplant surgery for lung cancer patient. According to many factors like age, disease type, disease progression, and various causes of underlying diseases, lung transplantation can be divided into double lung transplantation, single lung transplantation, combined heart and lung transplantation, and lobar transplantation. Toronto General Hospital, which has the largest volume of lung transplants in the world, only considers single-lung transplantation when one-sided lung tissue cannot be used. The median survival of patients undergoing double lung transplantation is significantly higher than that of single lung transplantation. 50.4 months $(\mathrm{P}<0.05)$ [5]. Common complications after lung transplantation include reperfusion pulmonary edema pulmonary infection, acute rejection, chronic rejection, anastomotic stricture. pneumothorax and pleural effusion. However, malignant tumors after lung transplantation are relatively rare [6-8].

\section{Post transplant Lymphoproliferative Disorders}

\section{Epidemiology of PTLD}

PTLD is substantial lymphocyte proliferation which generally occurs in solid organ transplantation (SOT) or hematopoietic stem cell transplantation (HSCT) (heterologous). Epidemiology is related to many factors. PTLD occurs after SOT is more common in the use of immunosuppressive agents, EBV infection, transplantation of 
organs such as heart and lungs; PTLD occurs after HSCT is more common in the lack of human leukocyte antigen matching. The incidence of PTLD after kidney transplantation was the lowest (0.8$2.5 \%)$, then increase in order by pancreas transplantation (0.5$5.0 \%)$, liver transplantation (1.0\%-5.5\%), heart transplantation (2.0\%-8.0\%), lung transplantation (3.0\%-10.0\%), multiple organs or intestines transplantation $(\leq 20 \%)$. The incidence of PTLD after heart, lung, and heart-lung transplantation is extremely high, with a five-year survival rate of $29 \%$ and median survival time of 10 month [9-10]. The incidence of PTLD after lung transplantation in children is even as high as $17.6 \%$ [11]. Lung is the only organ that can perform oxygen exchange without relying on blood perfusion. Not only respiratory organs, but also an immune organ, which may be related to the high incidence of PTLD. One research showed that the incidence of PTLD in SOT and HSCT don't have significant difference. However, PTLD patients have lower survival rate and faster disease progresses after HSCT [12].

\section{Clinical Performance and Auxiliary Examination}

PTLD has a variety of clinical manifestations, such as fever, fatigue, swollen tonsils, surface lymphadenopathy and relative organ symptoms, which can develop into multiple organ failure in days. Nodular lesion (83\%) and diffuse large b-cell lymphoma $(72 \%)$ are the most common manifestations. Involvement of bone marrow and central nervous system is uncommon $(<13 \%)$. Bone marrow infiltration, low serum albumin value $(<30 \mathrm{~g} / \mathrm{L})$, halo sign in chest computed tomography (CT) and late-onset PTLD are the bad sign of prognosis [13]. Usually in chest CT, PTLD presents multiple pulmonary nodules in the periphery and bottom of the lung which have clear boundaries and generally lack of bronchial gas phase and necrosis [14]. In 2017, World Health Organization classified PTLD pathological types into six categories: 1. nondestructive PTLD: plasmacytic hyperplasia; 2 . nondestructive PTLD: infectious mononucleosis-like PTLD; 3. nondestructive PTLD: florid follicular hyperplasia; 4. polymorphic PTLD; 5. monomorphic PTLD; 6. classic Hodgkin's lymphomas [15-16]. The clinical symptoms of PTLD and the graft-versus-host response (GVHD) are easily confused with one another. Early pathological biopsy is recommended if it is possible.

\section{Depletion of Immune Cells}

In the short term after lung transplantation, large doses of immunosuppressive agents and hormones are required during the induction period to suppress acute rejection. This action can lead the incidence rate drop to $13.3 \%$ [17]; mostly oral immunosuppression to maintain effect in long term. The anti-rejection effect of immunosuppressive agents was significant, but the depletion of T-lymphocytes became a risk factor for PTLD (RR: 8.4-15.8\%). Triple Immunosuppressive agents (tacrolimus, mycophenolate mofetil, prednisone) are the recommended program in maintenance phase. Tacrolimus was used in $83 \%$ of patients within 1 year after lung transplantation and $77 \%$ of patients within 5 years, unfortunately it has been shown to be an independent risk factor for the development of PTLD [18-19]. Some researchers have found that the occurrence of non-Hodgkin's lymphomas might be related to the production of abnormal NK cells. The expression of specific activated receptors NKp30, NKp46, and NKG2D value are low. Perforin expression is drastically reduced, and immunosuppressive agents have nothing to do with it [20].

\section{Viral Infection}

PTLD lesions mostly originate from EBV-infected B-lymphocytes, and if immune system can't defeat it, it will turn into tumor cells. EBV (+) patients have at least 4 times increase in PTLD after transplantation, especially in patients with early-onset [21]. About $30 \%$ of EBV (+) PTLD patients have tonsil swelling, but it often means benign lesions [22]. Young patients are likely to manifest as swollen lymph nodes in neck, yet older patients are likely to manifest as pulmonary nodules [22]. EBV positive is not a diagnostic basis, similarly, measuring EBV viral load in peripheral blood does not aid diagnosis. However, EBV-encoded RNA in situ hybridization test is recommended in clinical practice [23]. Patients with cystic fibrosis have a higher risk of $\operatorname{EBV}(+)$ and $\operatorname{CMV}(+)$, which could lead to PTLD [24]. Cytomegalovirus (CMV) infection is the most serious viral infection after transplantation, and the guide recommends routine use of ganciclovir for 6-9 months during the perioperative period.

\section{Treatment Plan}

There are many clinical methods for the treatment of PTLD, including reducing the use of immunosuppressive agents, surgery, radiotherapy, chemotherapy, monoclonal antibody therapy, and antiviral therapy et cetera. Limiting and complete marginal lesions are mainly surgically removed; The effect of antiviral treatment is not clear yet and should be used as adjuvant therapy. The pulmonary nodules that were found after transplantation were to determine the quality of the disease. PET-CT was recommended and the accuracy was as high as $86 \%$ [25], but local radiotherapy was not highly recommended [26].

a. Reduce the use of immunosuppressive agents: reducing the half dosage of calcineurin inhibitors and discontinuing unnecessary dose of glucocorticoid or anti-tumor meta advantages metabolism drugs could drop the incidence of PTLD by $20-80 \%$. Clinicians should weigh the and disadvantages about immunosuppressive agents, which should not cause a strong rejection, like GVHD. One research has pointed out the routine use of R-CHOP does not increase the incidence of PTLD without using CsA [27]. 179 patients who underwent lung transplant surgery in Japan during period 2001-2010. 18 patients of it developed malignant tumors (PTLD, 12 cases), and 14 patients were controlled after reducing or stopping the use of immunosuppressive agents [28]. Unfortunately, one research has showed that mortality rate of PTLD patients were still 50\% even after reducing immunosuppressive agents [29];

b. Rituximab: usually it came after with failure of reducing immunosuppressive agents. We recommend $375 \mathrm{mg} / \mathrm{m} 3$. Complete remission rate fluctuates at $20 \%-55 \%$. In addition, increasing the dosage of rituximab will also have a positive effect on the remission rate, especially on CD 20(+) PTLD patients [29-31]. Rituximab can be even at first-line therapy for PTLD [32]; 
c. Chemotherapy: The use of chemotherapeutic agents is generally used in patients with PTLD-based lymphomas, or after the ineffectiveness of the above two treatment options. CD20 (+) patients can add rituximab;

d. Re- transplantation: Its incidence is $2.4 \%$. Early retransplantation (within 1 month), male donor, and renal insufficiency are the bad sign of prognosis [33]. The second transplantation should be 1 year later from the PTLD treatment.

\section{Forward}

One study has investigated infusion of EBV-specific cytotoxic T lymphocytes into EBV (+) PTLD patients, with response rates as high as $80 \%(8 / 10)$ [34], which is extremely effective. Transfusion of donor's immune cells is in the field of adoptive cellular immunotherapy. Not only its hard to popularize, but also it could lead to serious complications like GVHD. The increasing incidence of PTLD has gradually attracted the attention of medical researchers. Nowadays, drug target like checkpoint Inhibitors. Anti-CD30 antibody BTK Inhibitors P13K Inhibitors and mTOR79 are the researchers focus. The reasons why the incidence of PTLD is very high after heart or pulmonary organ transplantation, why EBV (-) transplant patients occur PTLD, and why EBV (+) adult transplant patients of PTLD mostly manifest as pulmonary nodules are the direction of the research.

\section{Conclusion}

At present, only 20 hospitals in China have the qualification for lung transplantation. Donor of dead prisoners has been banned in China since 2015, and number of transplant operations has been greatly reduced without hesitating. In all organ donations in 2016, the lungs accounted for only 5\% (204 cases). Comparing to transplantation of corneal or kidney, it only confirmed one truth that our country still has a long journey to run. Post-surgery is a complex long-term management even after transplant surgery. PTLD is a rare but serious complication which requires clinician have ability to identify with GVHD, actively adjust the treatment plan, and record the clinical data for later study.

\section{References}

1. Liu ML (2013) Establishment of rat chronic allograft rejection rejection model and its relationship with IL-17[D]. Huazhong University of Science and Technology.

2. Chen JY (2017) Strive to build a lung transplant team that meets international standards [J]. Practical Organ Transplantation E-Journal.

3. Taylor DO, Edwards LB, Boucek MM, Trulock EP, Aurora P, et al. (2007) Registry of the International Society for Heart and Lung Transplantation: Twenty- fourth Official Adult Heart Transplant Report-2007[J]. Journal of Heart \& Lung Transplantation the Official Publication of the International Society for Heart Transplantation 26(8): 769-781.

4. Chen F, Yamane M, Inoue M, T Shiraishi, T Oto, et al. (2011) Less Maintenance Immunosuppression in Lung Transplantation Following Hematopoietic Stem Cell Transplantation from the Same Living Donor[J]. American Journal of Transplantation Official Journal of the American Society of Transplantation \& the American Society of Transplant Surgeons 11(7): 1509-1516.

5. Schaffer J M, Singh S K, Reitz B A, Zamanian RT, Mallidi HR, et al. (2015) Single-vs double-lung transplantation in patients with chronic obstructive pulmonary disease and idiopathic pulmonary fibrosis since the implementation of lung allocation based on medical need[J]. Jama 313(9): 936-948.

6. De PM, Bonser RS, Dark J, Rosemary F Kelly, David Mc Giffin, et al. (2005) Report of the ISHLT Working Group on Primary Lung Graft Dysfunction part III: donor-related risk factors and markers[J]. Journal of Heart \& Lung Transplantation the Official Publication of the International Society for Heart Transplantation 24(10): 1460-1467.

7. Stehlik J, Edwards LB, Kucheryavaya AY, Aurora P, Christie JD, et al. (2010) The Registry of the International Society for Heart and Lung Transplantation: twenty-seventh official adult heart transplant report-2010[J]. Journal of Heart \& Lung Transplantation the Official Publication of the International Society for Heart Transplantation 29(10): 10891103.

8. Tanaka S, Chen Yoshikawa TF, Yamada T (2016) Malignancies after living-donor and cadaveric lung transplantations in Japanese patients[J]. Surgery Today 46(12): 1-5.

9. Kumarasinghe G, Lavee O, Parker A, Nivison Smith, Milliken S, et al. (2016) Post-transplant lymphoproliferative disease in heart and lung transplantation: Defining risk and prognostic factors[J]. Journal of Heart \& Lung Transplantation 34(11): 693-694.

10. Wudhikarn K, Holman CJ, Linan M, Blaes AH, Dunitz JM, et al. (2011) Post-transplant lymphoproliferative disorders in lung transplant recipients: 20-yr experience at the University of Minnesota[J]. Clinical Transplantation 25(5): 705-713.

11. Stréhn A, Szőnyi L, Kriván G, Kovács L, Reusz Gy, Szabó, et al. (2014) Orv Hetil 155(8): 313-318.

12. Tai R, Tirumani SH, Tirumani H, Shinagare AB, Hornick JL, et al. (2015) Is there a difference in post-transplant lymphoproliferative disorder in adults after solid organ and haematologic stem cell transplantation? Experience in 41 patients[J]. British Journal of Radiology 88(1052): 20140861.

13. Leyssens A, Dierickx D, Verbeken EK, Tousseyn T, Verleden SE, et al. (2017) Post-transplant lymphoproliferative disease in lung transplantation: a nested case-control study[J]. Clinical Transplantation 31(7).

14. Mucha K, Foroncewicz B, Palczewski P, Sułkowska K, Ziarkiewicz Wróblewska B, et al. (2013) Pulmonary post-transplant lymphoproliferative disorder with a CT halo sign. Ann Transplant 18(1): 482-487.

15. Swerldow SH, Webber SA, Chadburn A, Jaffe ES, Pileri SA et al. (2017) WHO classification of tumours of haematopoietic and lymphoid tissues, ( $4^{\text {th }}$ edn.), Lyon, France: IARC Press 2(2): pp.586.

16. Arber DA, Orazi A, Hasserjian R, Thiele J, Borowitz MJ, et al. (2016) The 2016 revision to the World Health Organization (WHO) classification of myeloid neoplasms and acute leukemia. Blood 127(20): 2391.

17. Pan XF, Fu SJ, Yang J (2017) Shanghai lung hospital 10 years of experience in lung transplantation. Chinese Journal of Thoracic Surgery 4(4): 224227.

18. Trulock EP, Edwards LB, Taylor DO, Boucek MM, Keck BM, et al. The Registry of the International Society for Heart and Lung Transplantation: twenty-first official adult lung and heart-lung transplant report--2004. J Heart Lung Transplant 23(7): 796-803.

19. Dayton JD, Richmond ME, Weintraub RG, Shipp AT, Orjuela M, et al. (2011) Role of immunosuppression regimen in post-transplant lymphoproliferative disorder in pediatric heart transplant patients. J Heart Lung Transplant 30(4): 420-425.

20. Baychelier F, Achour A, Nguyen S, Raphael M, Toubert A, et al. (2014) Natural killer cell deficiency in patients with non-Hodgkin lymphoma after lung transplantation. Journal of Heart \& Lung Transplantation 34(4): 604-612.

21. Kinch A, Baecklund E, Backlin C, Ekman T, Molin D, et al. (2014) A population-based study of 135 lymphomas after solid organ transplantation: The role of Epstein Barr virus, hepatitis C and diffuse 
large B-cell lymphoma subtype in clinical presentation and survival. Acta Oncologica 53(5): 669-679.

22. Akbas A, Tiede C, Lemound J, Maecker Kolhoff B, Kreipe H, et al. (2015) Post-transplant lymphoproliferative disorders with naso- and oropharyngeal manifestation. Transplant International 28(11): 12991307.

23. Parrish A, Fenchel M, Storch GA, Buller R, Mason S, et al. (2017) EpsteinBarr viral loads do not predict post-transplant lymphoproliferative disorder in pediatric lung transplant recipients: A multicenter prospective cohort study. Pediatric Transplantation 21(6).

24. Lowery EM, Adams W, Grim SA, Clark NM, Edwards L, et al. (2017) Increased risk of PTLD in lung transplant recipients with cystic fibrosis. J Cyst Fibros 16(6): 727-734.

25. Muller N, Kessler R, Caillard S, Epailly E, Hubelé F, et al. (2017) 18 F-FDG PET/CT for the Diagnosis of Malignant and Infectious Complications After Solid Organ Transplantation. Nuclear Medicine \& Molecular Imaging 51(1): 1-11.

26. Dierickx D, Habermann TM (2018) Post-Transplantation Lymphoproliferative Disorders in Adults [J]. New England Journal of Medicine 378(6): 549-562.

27. Martã Nez Calle N, Alfonso A, Rifã N J, Herrero, Errasti P, et al. (2017) First-line use of rituximab correlates with increased overall survival in late post-transplant lymphoproliferative disorders: retrospective, single-centre study. European Journal of Haematology 98(1): 38-43.

28. Miyazaki T, Oto T, Okumura M, Date H, Shiraishi T, et al. (2016) De novo malignancy after lung transplantation in Japan.[J]. General Thoracic \& Cardiovascular Surgery 64(9): 543-548.

ISSN: 2574-1241

DOI: 10.26717/BJSTR.2018.07.001568

Jun Chen. Biomed J Sci \& Tech Res

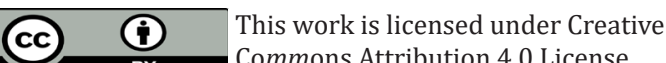

Submission Link: https://biomedres.us/submit-manuscript.php
29. Correlation between postoperative lymphoproliferative disorders and gastrointestinal tract in lung transplant patients: a case report [J]. World Core Medical Journal Digest: Gastrointestinal Diseases, 2006(Z1): 18-19.

30. Gupta S, Fricker FJ, Gonza lez Peralta RP, Slayton WB, Schuler PM, et al. (2010) Post-transplant lymphoproliferative disorder in children: recent outcomes and response to dual rituximab/low-dose chemotherapy combination. Pediatric Transplantation 14(7): 896-902.

31. Gholipour Shoiili A, Gholipour Shoiili H, Taheri S (2014) CD20 antigen expression by lymphoma cells in lung allograft recipients is associated with higher remission rate and superior survival: A study on heart and lung transplant recipients. Saudi Journal of Kidney Diseases \& Transplantation an Official Publication of the Saudi Center for Organ Transplantation Saudi Arabia 25(1): 29-37.

32. Hertig A, Zuckermann A (2015) Rabbit antithymocyte globulin induction and risk of post-transplant lymphoproliferative disease in adult and pediatric solid organ transplantation: An update. Transplant Immunology 32(3): 179-187.

33. Vickers MA, Wilkie GM, Robinson N, Rivera N, Haque T, et al. (2014) Establishment and operation of a Good Manufacturing Practicecompliant allogeneic Epstein-Barr virus (EBV)-specific cytotoxic cell bank for the treatment of EBV-associated lymphoproliferative disease. British Journal of Haematology 167(3): 402-410.

34. Kawut S, Lederer DS, Wilt J, Keshavjee S, Daly T, et al. (2008) Outcomes after lung retransplantation in the modern era.[J]. American Journal of Respiratory \& Critical Care Medicine 177(1): 114-120.

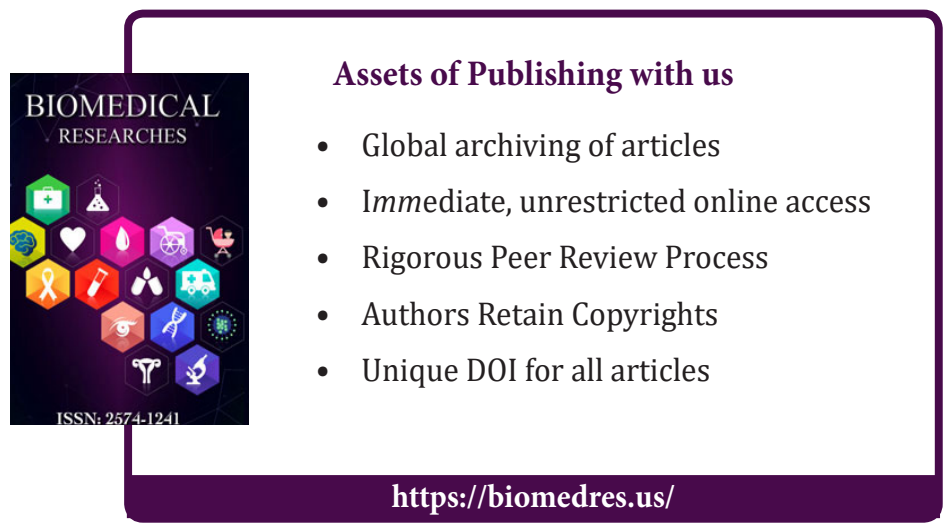

